\title{
Havalimanı Çalışanlarının Acil Durumlara Yönelik Hazırlığı ve Kriz Yönetimi
}

\author{
Cihan ÖNEN ${ }^{*}$, Yılmaz ÇífTÇİ ${ }^{2}$, Sedat KAYAR ${ }^{2}$ \\ ${ }^{1}$ Bitlis Eren Üniversitesi, Sağlık Yüksekokulu, Hemşirelik Bölümü, Bitlis, Türkiye \\ ${ }^{2}$ Bitlis Eren Üniversitesi, Fen Bilimleri Enstitüsü, Acil Durum ve Afet Yönetimi ABD, Bitlis, Türkiye \\ (ORCID: 0000-0002-9159-7396) (ORCID: 0000-0001-6200-2835) (ORCID: 0000-0002-8241-8798)
}

\begin{abstract}
$\ddot{O} \mathbf{z}$
Acil durum hadisesi herhangi bir zamanda herhangi bir yerde meydana gelen durumlardır. Önlenemeyen ya da kontrol altına alınamayan bu durum yolcu ölümleri, yaralanması, sakatlanması, hava taşımacıllğının sekteye uğraması, kargoların zarar görmesi gibi pek çok olumsuz duruma sebebiyet verebilir. Havalimanında koruyucu tedbirler ve iyi bir acil durum hazırlığı ile bu problemlerin büyük kısmı önlenebilir. Bu çalışmanın amacı havalimanında çalışan personellerin meydana gelecek acil durumlara hazırlıklı olma durumları değerlendirmek ve kriz yönetimi ile karşılaşıırmaktır. Kesitsel olarak planlanan çalışmanın kapsamını Batman Havalimanı ile Van Ferit Melen Havalimanı çalışanları oluşturmaktadır. Covid-19 pandemisinden dolayı araştırmaya katılmaya gönüllü kişilere internet ortamından ulaşılmıştır. Araştırmaya katılan bireylerin çoğunluğu acil duruma hazırlık çalışmalarının kapsamı, anlamı ile ilk yardıma dair içerikleri bilmektedir. Fakat ilk yardıma dair eğitim bilgisi daha kısıtlı kalmaktadır. Acil durum öncesi tatbikata katılanlar, acil duruma tanıklık edenler, acil durum ekibinde yer alma isteyenler, acil durumda soğuk kanlılığını koruma düşüncesinde olanlar, acil durum numarasını bilenler ve acil durum alarm anlamını bilenlerde kriz yönetimi puanı daha yüksektir. Fakat bu değişkenler ile kriz yönetimi arasında anlamlı fark yoktur. Acil duruma kendilerini hazır hissedenlerde kriz yönetimi puanı istatiksel olarak anlamlı bir şekilde daha yüksektir. Sonuç orak acil duruma dair bilgi sahibi olanlar ve duyusal olarak kendini acil duruma hazır hissedenler daha iyi kriz yönetmektedir. Havalimanı gibi kritik yerlerde kriz yönetiminin sürdürebilir ve sürekli olması açısından acil durum hazırlıklarına ağırlık verilmelidir. Katılımcıların ilk yardıma dair hizmet içi eğitim ihtiyacı giderilmelidir.
\end{abstract}

Anahtar kelimeler: Havalimanı çalışanları, Acil durum, Kriz yönetimi.

\section{The Emergency Preparedness and Crisis Management of the Airport Staff}

\begin{abstract}
An emergency event is a situation that occurs anywhere at any time. These events, which cannot be prevented or controlled, may cause many negative situations such as passenger deaths, injuries, injuries, disruption of air transport, and damage to cargo. Most of these problems can be avoided with protective measures and good emergency preparedness at the airport. The aim of this study is to evaluate the preparedness of the personnel working at the airport for emergencies and to compare them with crisis management. The scope of the crosssectional study consists of Batman Airport and Van Ferit Melen Airport employees. Due to the Covid-19 pandemic, people who volunteered to participate in the research were reached via the internet. The majority of the individuals participating in the research know the scope and meaning of emergency preparedness studies and the contents of first aid. However, educational knowledge on first aid remains more limited. Crisis management score is higher for those who participated in the pre-emergency drill, witnessed the emergency, wanted to take part in the emergency team, who thought of keeping their cool in an emergency, who knew the emergency number and who knew the meaning of emergency alarm. However, there is no significant difference between these variables and crisis management. Crisis management score is statistically significantly higher in those who feel ready for an emergency. As a result, those who have knowledge of the emergency situation and feel emotionally ready for the emergency manage the crisis better. In critical places such as airports, emergency preparations should be
\end{abstract}

\footnotetext{
*Sorumlu yazar: conen@beu.edu.tr

Geliş Tarihi: 02.08.2021, Kabul Tarihi: 08.10.2021
} 
emphasized in order to ensure the sustainability and continuity of crisis management. Participants' need for inservice training on first aid should be met.

Keywords: Airport Staff, Emergency, Crisis management.

\section{Giriş}

Acil durum, her an ve her yerde veya zamanda meydana gelebilecek hadisedir [1]. Bu durumun meydana gelmesi havalimanlarında havacılık faaliyetlerinin zarar görmesine, yolcu ölümlerine, kargoların ise büyük hasarlar görmesine neden olabilmektedir. Ayrıca havalimanı terminalleri de meydana gelebilecek bir acil durum ya da afette büyük hasarlar görerek işlevini kaybedebilmektedir [2]. Bu nedenle havalimanları kendi bünyelerinde meydana gelebilecek olaylara karşı acil durum hazırlık çalışmaları yapmaktadır. Havalimanlarında görev alan tüm personellerin oluşacak bir acil olaya nasıl yaklaşması gerektiği hususu önem arz etmektedir. Kurum içi verilen eğitimler ve kapsamlı tatbikatlar doğabilecek herhangi bir acil durumda doğru ve hızlı tepkilerin verilmesini sağlar [3].

Havalimanlarında acil durumlara yönelik hazırlanan planlama havalimanlarında oluşacak uçak kazası, doğal afet, meteorolojik hadiseler, toplu zehirlenme vakaları ve terminalde meydana gelebilecek acil durumlara karşı nasıl hareket edilmesi hususunda yol gösterici olmaktadır. Acil durum planı, olayın vuku bulmasıyla oluşan hasarın veya zararın azaltılması ve durumun normale dönmesi için gerekli olan tüm protokolleri içinde barındırmaktadır [4]. Olaylara ve oluşacak afetlere yönelik müdahale edecek olan personel ve liman birimlerinin sorumlulukları planlamada belirlenmektedir. Ayrica acil duruma müdahale etmek için havalimanı dışında gelecek olan kurum-kuruluşlarda görev alacak personel ile kullanılacak tesis, ekipman ve malzemelerin miktarları da planlamada açıklanır [5].

Havalimanlarında acil duruma karşın ortaya çıkacak krizin en iyi şekilde yönetilmesi önem taşımaktadır. Kriz yönetimi, yapılması gereken çalışmaların plan ve program dâhilinde yönetilememesi durumunda işleme konulacak bir plan ve olası tehdite karşın acil eylem planının devreye konulması durumudur [6]. Olayların her an yaşanabileceğini göz önüne alınarak kriz yönetiminin sürdürebilir ve sürekli olmasında fayda vardır. Kriz yönetiminde amaç, olayların meydana gelmesiyle alakalı olarak daha etkin bir şekilde müdahale etmek ve yürütülmesi düşünülen stratejilerin hayata geçirilmesini sağlamaktır [7]. Acil durumun öncesinde kriz yönetim ekibinin organize edilmesi ve havalimanlarında meydana gelecek acil durumlarla alakalı farklı senaryoların havalimanlarında oluşturacağı zararlar karşısında hangi adımların atılacağını ana hatlarıyla önceden belirlenmesi hayati öneme sahiptir.

Krizin meydana geleceği zamanlarda emir komuta zincirini net ve anlaşılır bir şekilde yerine getirecek olan kriz yönetim ekibi, olayın başından sonuna kadar tüm aşamalarda işin başında olmalıdır. Kriz yönetim ekibi, belirli aşamalarda yahut gerekli olan ihtiyaca göre hareket etmeli, olayın doğuracağı krizleri doğru metotla tartışıp yapılması gereken çalışmaları planlamalıdır. Acil durumun vaziyetine göre doğru strateji yapılmalı, havalimanının kendi bünyesindeki ekip ile protokol yapılan kurumlar planın detaylarını paylaşmalıdır. Kriz yönetim planı muhtemel acil durumlara karşı güvenilir ve etkin müdahaleyi içermelidir [8].

$\mathrm{Bu}$ çalışmada havalimanında çalışan personellerin meydana gelecek acil durumlara hazırlıklı olma durumlarının değerlendirilmesi ve kriz yönetimiyle karşılaştııılması amaçlanmıştır.

\section{Materyal ve Metot}

\subsection{Araştırmanın Kapsamı}

Devlet Hava Meydanları İşletmesi (DHMI), Türk Hava Yolları (THY), Yer Hizmetleri (Havaş, Çelebi) ve THY-OPET Batman Havalimanı ile Van Ferit Melen Havalimanında hizmet veren kurum ve kuruluşlardır. Her iki havalimanında toplam 302 kişi çalışmaktadır. Evrendeki kişi sayısı bilinen formülden $\mathrm{n}=(\mathrm{N} * \mathrm{t} 2 * \mathrm{p} * \mathrm{q}) /(\mathrm{d} 2 *(\mathrm{~N}-1)+\mathrm{t} 2 * \mathrm{p} * \mathrm{q})]$ örneklem sayıs1 169 olarak belirlenmiştir. Örnekleme alınıp çalışmaya katılmayı kabul edenlere Basit Rastgele Yöntem ile ulaşılmıştır. Covid 19 pandemi sürecinden dolayı çevrimiçi yolla örnekleme alınan çalışanlara ulaşmada güçlük yaşanmış teşviklere rağmen 105 kişi verileri doldurmuştur. Bu açıdan kesitsel nitelikteki bu çalışmanın kapsamını Batman Havalimanı ile Van Ferit Melen Havalimanında görev yapan ve bu çalışmaya katılmayı kabul eden 105 çalışan oluşturmaktadır. 


\subsection{Verilerin Toplanması ve Değerlendirilmesi}

Veri toplama aracı olarak araştırmacılar tarafından çalışmanın amacına uygun hazırlanmış anket ile geçerliliği Çalışkan A, 2020 tarafından yapılan Kriz Yönetimi ölçeği kullanılmıştır. Bu ölçek çalışanların kriz yönetimi uygulamalarına dair algılarını ölçmede kullanılmaktadır. Kriz Yönetimi Ölçeği 23 madden oluşmakta olup her bir maddesi "Kesinlikle katılmam 1, katılmam 2, kararsızım 3, katılırım 4, kesinlikle katılırım 5" beşli likert şeklindedir. Ölçekten düşük puan alınması kurumkuruluşun mevcut yapısıyla kriz faaliyetlerine düşük reaksiyonda cevap verebileceğini göstermektedir. Ölçeğin; kriz öncesi faaliyetler, kriz esansında faaliyetler ve kriz sonrası faaliyetler olmak üzere üç alt bileşeni vardır. Her bir alt bileşen ayrı ayrı değerlendirilebileceği gibi ölçek bir bütün olarak da değerlendirilebilmektedir. Kriz öncesi faaliyetler 9 maddeden, kriz esnas faaliyetler 10 maddeden ve kriz sonrası faaliyetler 4 maddeden oluşmaktadır. Güvenirliği açısından ölçek ile alt bileşenleri Cronbach Alfa testine tabi tutularak iç tutarlılığ 1 hesaplanmış ve güvenilir bulunmuştur [9]. Katılımcılara Şubat 2021-Mayıs 2021 tarihleri arasında mail ile ulaşılmış olup gönüllük esasına göre "Google form" ile veriler toplanmıştır.

\section{3. İstatistiksel Analizler}

Tanımlayıcı veriler sayı, yüzde ve aritmetik ortalama şeklinde sunulmuştur. İstatiksel anlamlılıkta $\mathrm{p}<0.05$ kullanılmıştır. Verilerin normal dağılıma uyup uymadığı Kolmogorov-Smirnov testi ve histogram dağ 1 lım grafiği ile değerlendirilmiştir. Çalışmada elde edilen veriler parametrik ve normal dağılım koşullarını sağladığından istatiksel değerlendirmede Independent Sample T-Testi ve One Way Anova Testi kullanılmıştır. Bağımsız değişkenlerden puan ortalaması daha yüksek çıkan gruplar kriz yönetimi daha yüksek olarak kabul edilmiştir.

\subsection{Etik Onay}

Bitlis Eren Üniversitesi Etik İlkeleri ve Etik Kurulunun 29.01.2021 tarih ve 21/1-V sayılı kararıyla çalışmanın etik oluru alınmıştır.

\subsection{Sinırlılıklar}

Covid 19 pandemi sürecinden dolayı veriler çevrimiçi olarak toplanmıştır. Anket toplama yüz yüze yapılmaması neticesinde araştırmacıların teşvikine rağmen anket ve ölçek sınırlı sayıda kişi tarafından doldurulmuştur. Çalışanların bazılarının pandemiden dolayı idari izinde olması, online süreç ve pandeminin getirdiği olumsuzluklardan dolayı veri toplanmasında güçlükler yaşanmıştır.

\section{Bulgular ve Tartışma}

Katılımcıların sosyodemografik özellikleri tablo 1'de sunulmuştur.

Tablo 1. Katılımcıların sosyo-demografik özellikleri ve kriz yönetimi karşılaştırılması

\begin{tabular}{|c|c|c|c|c|c|c|c|}
\hline Değişkenler & & $\mathbf{n}$ & $\%$ & Ortalama & ${ }^{b} \mathbf{S S}$ & & $\mathbf{p}$ \\
\hline \multirow[t]{2}{*}{ Cinsiyet } & Kadın & 8 & 7,6 & 83,75 & 8,99 & ${ }^{c} \mathrm{t}=-1,423$ & 0,158 \\
\hline & Erkek & 97 & 92,4 & 91,88 & 15,89 & & \\
\hline \multirow[t]{3}{*}{ Yaş } & $18-25$ & 19 & 18,1 & 85,68 & 16,52 & ${ }^{d} \mathrm{f}=1,583$ & 0,210 \\
\hline & $26-34$ & 53 & 50,5 & 91,94 & 14,03 & & \\
\hline & $35+$ & 33 & 31,4 & 93,36 & 17,13 & & \\
\hline \multirow[t]{2}{*}{ Medeni Durum } & Evli & 52 & 49,5 & 92,12 & 16,09 & ${ }^{c} \mathrm{t}=0,557$ & 0,579 \\
\hline & Bekar & 53 & 50,5 & 90,42 & 15,21 & & \\
\hline \multirow[t]{3}{*}{ Eğtim Düzeyi } & İlköğretim / lise & 14 & 13,3 & 98,93 & 14,97 & ${ }^{d} \mathrm{f}=3,399$ & $0,037^{\mathrm{a}}$ \\
\hline & Önlisans & 38 & 36,2 & 93,18 & 15,24 & & \\
\hline & Üniversite & 53 & 50,5 & 87,85 & 15,32 & & \\
\hline \multirow[t]{2}{*}{ Hizmet Süreniz } & $0-5$ y1l & 57 & 54,3 & 90,63 & 16,13 & ${ }^{{ }^{f}}=0,154$ & 0,857 \\
\hline & $6-10$ y1l & 21 & 20,0 & 91,14 & 12,25 & & \\
\hline
\end{tabular}




\begin{tabular}{llcccccc}
\hline & $11+$ & 27 & 25,7 & 92,67 & 17,16 & & \\
Çalıştı̆̆ı & Batman & 67 & 63,8 & 95,36 & 14,64 & ${ }^{\mathrm{c}} \mathrm{t}=3,802$ & $0,000^{\mathrm{a}}$ \\
Havalimanı & Van Ferit Melen & 38 & 36,2 & 84,03 & 14,74 & & $0,007 *$ \\
& DHMİ & 88 & 83,8 & 89,48 & 14,79 & $\mathrm{t}=-2,743$ & 0,03 \\
Çalıștı̆̆ı Birim & Diğer & 17 & 16,2 & 100,47 & 16,86 & & \\
\hline
\end{tabular}

${ }^{\mathrm{a}} \mathrm{p}<0.05,{ }^{\mathrm{b}} \mathrm{SS} ;$ Standart Sapma, ${ }^{\mathrm{c}}$; Independent Samples t Test, ${ }^{\mathrm{d}} \mathrm{f}$; One-Way Anova Test,

Eğitim düzeyi ile kriz yönetimi arasında istatistiksel olarak anlamlı fark bulunmuştur. Eğitim lise olanlarda kriz yönetimi puanı daha yüksektir.

Devlet Hava Meydanları İşletmesi (DHMI) dışındaki havalimanı çalışanlarının kriz yönetimi puanı DHMİ çalışanlarınınkinden istatistiksel olarak daha fazladır $(\mathrm{p}<0.05)$. DHMİ biriminde kriz yönetimi diğer birime göre daha düşüktür. Ayrıca Batman havalimanı çalışanlarının kriz yönetimi Van Ferit Melen Havalimanı çalışanlarına göre daha fazladır.

Yaşı genç olan havalimanı çalışanlarında kriz yönetimi puanı daha düşüktür. Yaşı küçük olanların mesleklerinde daha deneyimsiz olmaları ve mesleklerinin ilk zamanlarında henüz hizmet içi eğitim alamamaları kriz yönetimi algısını olumsuz yönde etkilemiş olabilir.

Tablo 2. Katılımcıların acil duruma dair hazırlıkları

\begin{tabular}{|c|c|c|}
\hline \multicolumn{3}{|l|}{ Katılımcılara göre Acil Durum Hazırlık Çalışmaları Kapsamında Yer Alması Gerekenler } \\
\hline Değişkenler & $\mathbf{n}$ & $\%$ \\
\hline Hizmet içi eğitim düzenleme & 87 & 82,9 \\
\hline Çalıştı̆̆1 yere ait acil durum planlaması & 86 & 81,9 \\
\hline Acil toplanma alanı bilme & 83 & 79,0 \\
\hline Acil durum alarmlarının ne anlama geldiğini bilme & 82 & 78,1 \\
\hline Acil çıkış kapılarının yerlerini bilme & 80 & 76,2 \\
\hline Acil durumlara dair kareli haritaların anlamını bilme & 75 & 71,4 \\
\hline \multicolumn{3}{|l|}{ Acil Durumun Anlamına Katılımcıların Verdiği Cevap } \\
\hline $\begin{array}{l}\text { İşyerinde olası herhangi bir kaynaktan meydana gelen ve acil müdahale, ilkyardım vb. gerektiren } \\
\text { durumlar, }\end{array}$ & 86 & 81,9 \\
\hline $\begin{array}{l}\text { İnsanların normal yaşam faaliyetlerini sekteye uğratan, yavaşlatan acil müdahale gerektiren } \\
\text { durumlar, }\end{array}$ & 79 & 75,2 \\
\hline Ani müdahale ihtiyacı olan beklenmedik ciddi durumlar, & 72 & 68,6 \\
\hline \multicolumn{3}{|l|}{ İlkyardımın Anlamını Bilme } \\
\hline $\begin{array}{l}\text { Yaşamı tehdit eden herhangi bir durumda sağlı görevlileri olay yerine gelip müdahaleyi } \\
\text { sağlayıncaya kadar mevcut olanaklar ile ilaçsız bir şekilde yapılan müdahale, }\end{array}$ & 70 & 66,7 \\
\hline İlkyardım yapılan kişiye ilaçla tedavinin uygulanmasıdır, & 7 & 6,7 \\
\hline \multicolumn{3}{|l|}{ İlk yardımın ‘ABC’sinin Kapsamı } \\
\hline Solunumun Değerlendirilmesi & 94 & 89,5 \\
\hline Hava Yolu Açıklığının Değerlendirilmesi & 93 & 88,6 \\
\hline Dolaşımın Değerlendirilmesi & 65 & 61,9 \\
\hline Sindirimin Değerlendirilmesi & 9 & 8,6 \\
\hline
\end{tabular}

Katılımcıların çoğunluğu acil duruma hazırlık kapsamında; hizmet içi eğitim verilmesi, kurumun acil durum planının olması, acil toplanma alanın bilinmesi, acil durum alarmlarını bilmesi ve acil çıkış kapılarını bilinmesi gerektiğini ifade ederek doğru cevap vermiştir. Yine katılıcıların çoğunluğu acil durumun anlamına dair bilgilerinin yeterli olduğu Tablo 2'de görülmektedir. Bu da katılımcıların acil duruma hazırlığına dair yeterli bilgilerinin olduğunu göstermektedir. Çalışanların acil durum veya afete dair bilgi düzeyinin artması bu tip durumlara karşı hazırlığı da artırmaktadır.

Katılımcıların ilkyardım ABC (Airway, Breathing, Circulation)'sine dair bilgilerine bakıldığında önemli çoğunluğu hava yolu ve solunum yolu açıklığını değerlendirmeyi bilse de yarısına yakını dolaşımın değerlendirilmesi gerektiğini bilmiştir. Havalimanı çalışanlarının acil duruma dair birçok konuda bilgilerinin yeterli olduğu bu çalışmada görülmektedir. Fakat ilk yardıma dair bilgilerinin acil durum kadar iyi olmadığı görülmektedir. Acil durum anında hayat kurtarılması bağlamında ilkyardım eğitimin havalimanı çalışanlarına verilmesi bu konuda bilgi ya da becerilerini artırabilmektedir [10]. 
Havalimanında çalışanların önemli çoğunluğu çalıştığı yere ait acil durum planlaması olması gerektiğini belirtmekte ve acil durum numaralarını bilmektedir. Küçük işletmelerde bu oran çok daha azdır. Havalimanı gibi acil durum yönünden kritik yerlerde hizmet içi eğitimin ve tatbikat daha fazla olması bu farklılıkta etkili olmuş olabilir [11].

Tablo 3. Katılımcıların acil duruma dair hazırlıkları ve kriz yönetimi ile karşılaştırılması

\begin{tabular}{|c|c|c|c|c|c|c|c|}
\hline Değișkenler & & $\mathbf{n}$ & $\%$ & Mean & ${ }^{\mathbf{b}} \mathbf{S S}$ & $\mathrm{c}_{\mathbf{t}}$ & p \\
\hline \multirow[t]{2}{*}{ Tatbikata Katılma } & Evet & 81 & 77,1 & 91,93 & 16,22 & 0,806 & 0,422 \\
\hline & Hayır & 24 & 22,9 & 89,00 & 13,32 & & \\
\hline \multirow[t]{2}{*}{ Havalimanında Acil Durum Tanıklığı } & Evet & 61 & 58,1 & 92,13 & 14,75 & 0,674 & 0,502 \\
\hline & Hayır & 44 & 41,9 & 90,05 & 16,80 & & \\
\hline \multirow[t]{2}{*}{ Acil Müdahale Ekibinde Görev Alma İsteği } & Evet & 94 & 89,5 & 91,51 & 15,63 & 0,485 & 0,629 \\
\hline & Hayır & 11 & 10,5 & 89,09 & 15,82 & & \\
\hline \multirow[t]{2}{*}{ Acil Duruma Kendini Hazır Hissetme } & Evet & 75 & 71,4 & 93,35 & 16,24 & 2,166 & $0,033^{\mathrm{a}}$ \\
\hline & Hayır & 30 & 28,6 & 86,03 & 12,63 & & \\
\hline \multirow[t]{2}{*}{ Acil Durumda Soğuk kanlığı Koruma } & Evet & 82 & 78,1 & 92,32 & 16,67 & 1,703 & 0,094 \\
\hline & Hayır & 23 & 21,9 & 87,48 & 10,38 & & \\
\hline \multirow[t]{2}{*}{ Acil Numarayı Bilme } & Evet & 98 & 93,3 & 91,41 & 15,61 & 0,370 & 0,712 \\
\hline & Hayır & 7 & 6,7 & 89,14 & 16,41 & & \\
\hline \multirow[t]{2}{*}{ Acil Durum Alarmın Anlamını Bilme } & Evet & 83 & 79 & 92,22 & 15,92 & 1,228 & 0,222 \\
\hline & Hayır & 22 & 21 & 87,64 & 14,07 & & \\
\hline
\end{tabular}

Acil durum öncesi tatbikata katılanlar, acil duruma tanıklık edenler, acil durum ekibinde yer almak isteyenler, acil durumda soğukkanlılı̆̆ını koruma düşüncesinde olanlar, acil durum numarasını bilenler ve acil durum alarmın anlamını bilenlerde kriz yönetimi puanı daha yüksektir. Fakat bu değişkenler ile kriz yönetimi arasında anlamlı fark yoktur $(\mathrm{p}>0,05)$.

Acil duruma kendilerini hazır hissedenlerde kriz yönetimi puanı anlamlı bir şekilde daha yüksektir ( $\mathrm{p}<0,05)$. Havalimanı çalışanlarının üçte ikisi kadarı kendini acil duruma hazır hissetmektedir. Literatürde hastane çalışanında ve genel toplumda afet, acil durum vb. durumlara hazır hissedenlerin daha az olduğu görülmektedir. Havalimanının kritik bölge olması ve çalışanlara yönelik daha fazla acil durum ya da afete hazırlık çalışmaları yapılması acil duruma hazırlık hissini artırmış olabilir $[12,13]$. Acil durum planlarının doğru bir şekilde hazırlanması ve sunulması havalimanı güvenliği ve kriz yönetimi için önem arz etmektedir [14]. Kendilerini acil duruma hazır hissedenlerin kriz yönetimine dair puanlarının daha yüksek olması acil duruma dair bilgi, tatbikat ve deneyimlerinin daha fazla olmasından kaynaklanmış olabilir. Krizler kurumlar üzerinde kaotik durumlar oluşturabilir. Kaynaklardan bilgilere ulaşabilen kişiler acil durum kriz yönetimine karşı daha hazırlıklı hissedebilmektedir Acil durumlar, afetler gibi durumlarda Kriz olasılığını tamamen önlemek mümkün olmasa da iyi bir hazırlık süreci ile en az hasarla kriz yönetilebilir $[13,15]$.

\section{Sonuç ve Öneriler}

Sonuç orak acil duruma dair daha fazla bilgi sahibi olanlar ve duyusal olarak kendini acil duruma hazır hissedenler kriz algısını daha iyi yönetebilmektedir. Havalimanı gibi kritik yerlerde kriz yönetiminin sürdürebilir ve sürekli olması açısından acil durum hazırlıklarına ağırlık verilmelidir. Acil durumda hayat kurtarılması bağlamında katılımcıların ilk yardıma dair hizmet içi eğitim ihtiyacı giderilmelidir.

Covid-19 pandemi süreci ve kurumlar tarafindan sadece online veri toplanmasina izin verildiğinden araştırma grubunun tamamına ulaşılamamıştır. Bu açıdan bu çalışmanın sonuçları sadece katılımcılar ile sınırlandırılabilir. Daha fazla havalimanı ve kişileri kapsayacak şekilde pandemi ve sonrasında daha kapsayıcı bir şekilde konu üzerinde çalışılabilir. 


\section{Teşekkür}

Anket verilerinin toplanmasında gerekli izin ve katkıları sağlayan Devlet Hava Meydanları İşletmesi Genel Müdürlüğü Van Ferit Melen Havalimanı Müdürlüğü ve Batman Havalimanı Müdürlüğüne teşekkür ederiz.

\section{Yazarların Katkısı}

Araştırmanın tasarımı, planlanması, tartışma, materyal ve metodunun önemli bir kısmı Cihan ÖNEN tarafından yazılmıştır. Yılmaz ÇİFTÇİ çalışmanın giriş, planlama ve tasarımına katkı sağlamıştır. Sedat KAYAR çalışmanın düzenlenmesi, özeti ve materyal ve metodunda katkıları olmuştur.

\section{Çıkar Çatışması Beyanı}

Çalışmada yazarlar arasında çıkar çatışması yoktur.

\section{Araştırma ve Yayın Etiği Beyanı}

Yazarlar araştırma ve yayın etiğine uymuştur.

\section{Kaynaklar}

[1] Turan M., Doğan G., Bulut Y., Öztürk G., Şahinöz S. 2018. Yükseköğretim kurumlarında afet ve acil durumlara hazırlık çalışmaları ve etkinlikleri Gümüşhane üniversitesi örneği. Gümüşhane Üniversitesi Sağlık Bilimleri Dergisi, 7(1): 1- 11

[2] International Civil Aviation Organization (ICAO) 2012. "Airport Services Manual (Doc 9137) Part 7 Airport Emergency Planning", 1-96 s. 1-2.

[3] International Civil Aviation Organization (ICAO) 2016 "Airport Services Manual (Doc 9137) Part 1 Rescue and Fire Fighting" 1-163 s. 118.

[4] Koçak H., Yavuz Ö. 2012. Havalimanlarının afetlere hazırlanması. 1st International Aviation Management Conference, 7 December, Ankara, 130-136.

[5] Bolat Y.Z. 2015. Kamu Kurumlarında Acil Durum Planı Hazırlama Rehberi ve İlgili Sektörde Acil Durum Bilincini Artırmaya Yönelik Uygulama. 1-153 s. 7

[6] Kömürcüoğlu E. 2019. Kamu Kurumları Yönetiminde Liderlik ve Kriz Yönetimi. Turkish Studies Economics, Finance, Politics, 14 (4): 1423-1440.

[7] Akdağ M. 2005. Halkla ilişkiler ve kriz yönetimi. Selçuk Üniversitesi Sosyal Bilimler Enstitüsü Dergisi, 14: 1-20.

[8] Arslan A.H. 2019. Havacılıkta kriz yönetimi: Southwest havayolları örneği. Journal of Aviation Research, 1(1): 42-56.

[9] Çalışkan A. 2020. Kriz yönetimi: Bir ölçek geliştirme çalışması. Türk Sosyal Bilimler Araştırmaları Dergisi, 5(2): 106-120.

[10] Andsoy İ., Ural S. 2014. Bir devlet üniversitesinde görev yapan güvenlik personeline verilen ilkyardım eğitiminin etkinliğinin değerlendirilmesi. Çağdaş Tıp Dergisi,4(2): 84-90.

[11] Turan M., Kaya AA., Oral V. 2018. Küçük işletmelerin afet ve acil durumlara yönelik kurumsal hazırlıklarının değerlendirilmesi: Gümüşhane ili örneği. Gümüşhane Üniversitesi Sağlık Bilimleri Dergisi, 7(1): 12-16.

[12] İytemür A., Yeşil S.T. 2020. Bir üniversite hastanesinde çalışan hemşirelerin hastane afet ve acil durum planları ile ilgili görüşlerinin incelenmesi. Hacettepe Üniversitesi Hemşirelik Fakültesi Dergisi, 7(2): 138-148.

[13] Heath R.L, Lee J., Ni L. 2009. Crisis and risk approaches to emergency management planning and communication: The role of similarity and sensitivity. Journal of Public Relations Research, 21(2): 123-141.

[14] Kraus J., Plos V., Vittek P. 2014. The new approach to airport emergency plans. International Scholarly and Scientific Research \& Innovation, 8(8): 2406-2409.

[15] Demirtaş H. 2000. Kriz yönetimi. Kuram ve Uygulamalarda Eğitim Yönetimi, 23(23): 353-373. 